\title{
Association between different screening strategies for SARS-CoV-2 and deaths and severe disease in Italy.
}

\author{
Edoardo Mannucci ${ }^{1}$, Antonio Siilverii ${ }^{2}$, and Matteo Monami ${ }^{2}$ \\ ${ }^{1}$ University of Florence \\ ${ }^{2}$ Affiliation not available
}

April 28, 2020

\begin{abstract}
Background The WHO recommends testing any suspected person with Severe Acute Respiratory Syndrome CoronaVirus-2 (SARS-CoV-2), in order to limit the spread of the epidemic. In Italy, some Regions opted for extensive testing, whereas others limited tests to selected subjects. To assess the influence of different strategies, we examined the incidence of death and severe cases in Italy. Methods Data on new cases of SARS-CoV-2, number of tests, deaths, and admissions to Intensive Care Units (ICU) were retrieved in each Italian Region, from February 24th to March 18th, 2020. As an index of different screening strategies, the number of tests/positive test results (T/P) ratio as of March 7th, 2020, was considered. The cumulative number of deaths and of new severe cases, between March 23thand 25th was recorded. The association of those two outcomes with the number of $\mathrm{T} / \mathrm{P}$ ratio was assessed using linear regression models. Results In the interval between March 23th-25th, recorded deaths (*million inhabitants) were 14(3-54), whereas severe cases were 31(10-112). Both the number of deaths and that of severe cases showed a significant correlation ( $\mathrm{R} 2.38$ and .37 , with $\mathrm{p}<.01$ ) with the $\mathrm{T} / \mathrm{P}$ ratio. Deaths and severe cases were associated with higher mean personal income and lower density of General Practioners (GPs). The association of T/P with severe cases and deaths retained statistical significance after adjusting for mean personal income (R2 .20 and .21, respectively; both $\mathrm{p}=.04)$ and GPs density (R2.22 and .21, respectively; both $\mathrm{p}=.03$ ). Conclusions A more aggressive screening strategy for SARS-Cov-2, was associated with lower rates of death and severe disease in Regions of Italy.
\end{abstract}

\section{Introduction}

The World Health Organization recommends to test any suspected person with Severe Acute Respiratory Syndrome CoronaVirus-2 (SARS-CoV-2) ${ }^{1}$, in order to isolate positive individuals, limiting the spread of the epidemic. On the other hand, extensive isolation of oligosymptomatic infected people and of their close contacts, including many healthcare professionals, could reduce the efficiency of healthcare systems in responding to the epidemic. These different viewpoints are currently debated in Italy, where the healthcare system has a Regional organization; different Regions have adopted opposite strategies in this respect. Some Regions (e.g., Veneto) opted for extensive testing, thus organizing laboratory facilities, whereas others (e.g., Lombardia, Emilia-Romagna, and Piemonte) limited diagnostic tests to selected subjects. Conversely, social distancing and isolation measures (including lockdown) were decided at a National level. To assess the potential influence of different testing strategies, we examined the incidence of death and severe cases in 19 regions of Italy.

\section{Methods}

We retrieved daily data on new cases of SARS-CoV-2 (i.e., individuals with positive test results), number of tests (reverse transcription polymerase chain reaction; RT-PCR) performed, deaths, and admissions to Intensive Care Units (ICU) in each Region, from February $24^{\text {th }}$ to March $18^{\text {th }}, 2020$, obtained from the 
Health Ministry website ${ }^{2}$. Demographic, socioeconomic and healthcare organization data were retrieved from the National Institute of Statistics (ISTAT) ${ }^{3}$.

As an index of different screening strategies, the number of tests/positive test results (T/P) ratio as of March $7^{\text {th }}, 2020$, was considered. The subsequent evolution of the epidemic was assessed through the cumulative number of deaths and of new severe cases, between March $23^{\text {th }}$ and $25^{\text {th }}$, inclusive; the latter were defined as a composite of death and admission to ICU. This work is based on publicly available data, needing no ethical approval.

The association of those two outcomes with the number of $\mathrm{T} /$ Pratio at March 7th was assessed using a linear regression model. For each confounder significantly associated with outcomes, multivariate linear regression models were applied to assess the independent contribution of $\mathrm{T} / \mathrm{P}$, assuming two-sided $\mathrm{p}<.05$ as significant. Analyses were performed on SPSS (SPSS-Inc., Chicago, IL, USA) 25.0.

\section{Results}

The median number of tests per million inhabitants performed as of March $7^{\text {th }}$ in different Regions (with interquartile range) was 240 (105-474), ranging from 58 to 2941. The median prevalence of known SARSCoV-2 infection was 27 (7-64) cases per million, ranging from 2 to 273 . The number of tests and that of individuals with positive test results showed a significant correlation $(\mathrm{r}=0.61, \mathrm{p}=0.006)$. The $\mathrm{T} /$ Pratio was 11.2 (5.0-19.8), with a range of 3.6-28.2. In the interval between March $23^{\text {th }}$ and $25^{\text {th }}$, recorded deaths per million inhabitants were 14(3-54), with a range of 2-119, whereas severe cases (ICU+death) were 31(10-112), ranging from 4to 271. Both the number of deaths and that of severe cases on March $23^{\text {th }}-25^{\text {th }}$ showed a significant correlation $\left(\mathrm{R}^{2} .38\right.$ and .37 , with $\mathrm{p}=.004$ and .006 , respectively) with the $\mathrm{T} / \mathrm{P}$ ratio up to March $7^{\text {th }}$ (Figure 1). With the exclusion of apparent outlier Lombardia, $\mathrm{R}^{2}$ for the correlation of deaths and severe cases were $.36(\mathrm{p}=.009)$ and $.34(\mathrm{p}=.01)$, respectively.

Deaths and severe cases were associated with higher mean personal income and lower density of General Practioners (GPs); deaths were also associated with higher population density (Table 1). The association of $\mathrm{T} / \mathrm{P}$ with severe cases and deaths retained statistical significance after adjusting for mean personal income $\left(\mathrm{R}^{2} .20\right.$ and .21 , respectively; both $\left.\mathrm{p}=.04\right)$ and GPs density $\left(\mathrm{R}^{2} .22\right.$ and .21 , respectively; both $\left.\mathrm{p}=.03\right)$.

\section{Discussion}

A higher number of tests/positive test results ratio, reflecting a more aggressive screening strategy for SARS-Cov-2, was associated with lower rates of death and severe disease in Regions of Italy. Although the association was maintained after adjusting for some confounders, the possibility of other unaccounted confounders cannot be excluded. Moreover, results are specific for the time range considered. Despite these limitations, this association should be considered by policy-makers in other Countries faced by the threat of the epidemic.

\section{References}

1. https://www.who.int/emergencies/diseases/novel-coronavirus-2019/events-as-they-happen; Accessed April $1^{\text {st }}, 2020$.

2. https://github.com/pcm-dpc/COVID-19/blob/master/dati-regioni/dpc-covid19-ita-regioni.csv; Accessed April $1^{\text {st }}, 2020$.

3. http://dati.istat.it/; Accessed April 1 ${ }^{\text {st }}, 2020$.

\section{Acknowledgment section}

\section{Conflict of Interest Disclosures}

Dr Monami reports personal fees from Astra Zeneca,personal fees from Boehringer-Ingelheim, personal fees from Eli-Lilly, personal fees from Novo Nordisk, personal fees from Sanofi, and personal fees from Takedaoutside the submitted work; Dr Mannucci reports grants and personal fees from AstraZeneca, personal fees from Abbott, grants and personal fees from Boehringer Ingelheim, grants and personal fees from Eli Lilly, grants 
from Genentech, grants from Molteni, personal fees from Merck, grants and personal fees from Novo Nordisk, and personal fees from Sanofi outside the submitted work.

\section{Role of funding}

This research was performed as a part of the institutional activity of the unit, with no specific funding. All expenses, including salaries of the investigators, were covered by public research funds assigned to the unit.

\section{Access to data and Data Analysis}

The corresponding author had full access to all the data in the study and takes responsibility for the integrity of the data and the accuracy of the data analysis.

\section{Legend to figure}

Figure 1 - Association of screening strategies with the outcome of the SARS-CoV-2 infection. Linear regression models for the association of severe cases (panel A) and deaths (panel B) on March $23^{\text {rd }}-25^{\text {th }}$ with the number of tests/positive test results ratio up to March $7^{\text {th }}$.

\section{Tables}

Table 1 - Unadjustedlinear regression models for the association of deathsand severe caseswith different parameters.

\begin{tabular}{|c|c|c|c|c|}
\hline & & & $23^{\text {rd }}-25^{\text {th }}$ March & $23^{\text {rd }}-25^{\text {th }}$ March \\
\hline Parameters & Median [quartiles] & Range & $\begin{array}{l}\text { Deaths } \\
R^{2}\end{array}$ & $\begin{array}{l}\text { Deaths } \\
p\end{array}$ \\
\hline Age (years) & $45[44-46]$ & $42-48$ & .23 & .35 \\
\hline Age[?]65 years $(\%)$ & 23 [21-25] & $20-30$ & .27 & .28 \\
\hline Urbanization rate $(\%)$ & $25[17-36]$ & $0-60$ & .20 & .41 \\
\hline Density (inh./Km²) & 162 [104-267] & $39-424$ & .31 & .21 \\
\hline Personal income (1000\euro/inh.) & $30[25-32]$ & $22-35$ & .62 & .006 \\
\hline Public health expenditure (\euro/inh.)\# & 1848 [1804-2022] & $1730-2113$ & .18 & .47 \\
\hline Intensive Care beds/mln*inh $\#$ & $81[74-100]$ & $23-307$ & .05 & .83 \\
\hline General Practitioners/mln*inh.\# & 735 [692-809] & $623-852$ & .65 & .003 \\
\hline
\end{tabular}

*2019; mln: million; inh.: inhabitants.

\section{Figure 1}

Panel A 




Panel B



